\title{
Vestibulo-ocular reflex and the head impulse test
}

\author{
Reflexo vestíbulo-ocular e o teste do impulso da cabeça \\ Eliana T. Maranhão', Péricles Maranhão-Filho²
}

\begin{abstract}
The authors highlights the importance of the vestibulo-ocular reflex examination through the head impulse test as a diagnostic method for vestibular dysfunction as well as, and primarily, a bedside semiotic resource capable of differentiating between acute peripheral vestibulopathy and a cerebellar or brainstem infarction in emergency rooms.
\end{abstract}

Key words: Head Impulse Test, nystagmus, dizziness, acute peripheral vestibulopathy, stroke.

RESUMO

Os autores ressaltam a importância do exame do reflexo vestíbulo-ocular por meio do teste do impulso da cabeça como método diagnóstico de hipofunção vestibular. Este método é também - e principalmente - um instrumento semiótico de beira do leito capaz de auxiliar no diagnóstico diferencial entre a vestibulopatia periférica aguda e o infarto cerebelar ou do tronco cerebral na sala de emergência.

Palavras-Chave: Teste do Impulso da Cabeça, nistagmo, tontura, vestibulopatia periférica aguda, acidente vascular cerebral.

Vertigo and dizziness are among the most frequent complaints in medical practice. These are symptoms that become more common with age, and therefore indicate a higher prevalence in a not too distant future ${ }^{1,2}$. The history and the neuro-otological examination of these patients are essential in identifying any underlying disease. Except for some otolaryngologists, the vast majority of professionals interested in investigating and treating vestibular symptoms, including vestibular rehabilitation therapists and general neurologists, is not armed with the necessary tools for the investigation of the vestibular system. Hence the importance of simple and effective bedside tests like the head impulse test (HIT) which does not depend on instruments - in evaluating patients with vertigo, dizziness, and imbalance complaints ${ }^{3}$. The authors highlight the importance of routine tests of vestibulo-ocular reflex (VOR) through the HIT, as well as in the emergency care department.

\section{VESTIBULO-OCULAR REFLEX}

The VOR is a phylogenetic old and simple reflex that involves only three neuronal pathways ${ }^{4}$. The first goes from the peripheral vestibular organs to the vestibular nuclei - lateral, medial, superior, and inferior — besides a number of other small ones with little known functions ${ }^{5}$. The second goes from there to the oculomotor nuclei, and the third pathway reaches the extra-ocular muscles. The dynamic properties of the VOR mature in the first two months of human life; the amount of time required for visual information to become available and begin providing the necessary signals to stimulate the neuronal network for the reflex ${ }^{6}$. The VOR operates by generating eye movements at the same speed but in opposite direction to the head movement. Its function is to stabilize the image on the fovea during head movement, thus allowing the person to see a sharp and clean image even during movement. With a latency period of only 8 to $12 \mathrm{~ms}$, this reflex is considered the fastest in humans.

The gain of the VOR is defined as "output" divided by "input." In order to keep the fovea fixed on the target, the "output"(VOR) has to be equal to the "input"(drive head) and the gain of VOR very close or equal to one ${ }^{7}$. If the vestibular system functions normally, when applying a high frequency stimulation $\left(\sim 122^{\circ} /\right.$ second $)$ as a jerk to the head, the gain of the VOR is very close to $1(0.94 \pm 0.08$ standard deviation). In case of a very fast pulse $(>10 \mathrm{~Hz})$ the VOR is employed rather

Brazilian National Cancer Institute (INCA), Rio de Janeiro RJ, Brazil.

${ }^{1} \mathrm{PT}, \mathrm{MSc}$, certified by the American Physical Therapy Association for Vestibular Rehabilitation, Alexandria VA, USA.

${ }^{2}$ Professor of Neurology at Clementino Fraga Filho Hospital, Universidade Federal do Rio de Janeiro (UFRJ), Rio de Janeiro RJ, Brazil.

Correspondence: Eliana Teixeira Maranhão; Avenida das Américas 1.155 / sala 1.705; 22631-000 Rio de Janeiro RJ - Brasil; E-mail: limaranhao@gmail.com

Conflict of interest: There is no conflict of interest to declare.

Received 13 May 2012; Received in final form 13 May 2012; Accepted 25 May 2012 
than the optokinetic system, resulting in a compensatory ocular deviation of the same magnitude and opposite direction in relation to the movement of the head. This keeps the eyes on target while the head rotates around the eyes ${ }^{7}$.

\section{HEAD IMPULSE TEST}

Described by Halmagyi and Curthoys ${ }^{8}$, in 1988, the HIT lends itself to detect unilateral or bilateral vestibular hypofunction through the VOR response, and is very easy to be applied. The examiner sits in front of the patient and asks the same to keep his eyes on the examiner's nose. The examiner holds the patient's head by the temporal-zygomatic region with both hands, inclining it forward at $30^{\circ}$ in order to maintain the plane of the horizontal canal parallel the ground, and quickly turns the patient's head in the horizontal plane $\left( \pm 2,000^{\circ} / \mathrm{sec}^{2}\right)$ alternating directions at random, and observes the patient's ability to keep the eyes fixed on target. The rotation does not need to be large (quite to the contrary — only 5 to $10^{\circ}$ ), but must have a high acceleration rate and unpredictable direction and timing. Normal response means the eyes remain fixed on the target. The response is abnormal when a corrective eye saccade makes up the end of the head movement in order to re-target ${ }^{6,9,10}$ (Figure). The rotation of the head one side at a time stimulates the horizontal semicircular canal to the rotation side provoking the VOR and the eyes move to the opposite direction. The HIT may be carried out in other planes as well.

If a bilateral vestibular dysfunction exists, the saccade of re-fixation will occur with the head being quickly turned to both sides. In the original study conducted with 12 patients who underwent complete vestibular nerve unilateral section, Halmagyi and Curthoys ${ }^{8}$ demonstrated $100 \%$ sensitivity and specificity using the HIT on the injuried side. In incomplete unilateral hypofunction, the most frequent situation in daily practice, the HIT sensitivity varies from 34 to $100 \%$ and the specificity from 81 to $100 \%{ }^{10}$. Schubert et al. ${ }^{12}$ found $71 \%$ sensitivity of the HIT in 79 patients with varying degrees of unilateral vestibular lesion and sensitivity of $84 \%$ in 32 patients with bilateral damage. The test's sensitivity increases when we look at three important details: 1) Tilting the patient's head $30^{\circ}$ forward; 2) moving it at unpredictable direction and time intervals; and 3) performing the maneuver more than once ${ }^{12-14}$. The HIT, when performed through active movement, has a great chance of generating false negative result ${ }^{15}$.

Comparatively, the caloric response is analogous to a rotational stimulus of $0.003 \mathrm{~Hz}$ (i.e. one cycle per 5.5 minutes), while the HIT represents a motion of high frequency characteristic to the movements that occur in normal daily life. It should be remembered that the peripheral vestibular disorders affect an early and more severe spectrum of low-frequency vestibular functions. This phenomenon greatly favors the caloric response, being more sensitive than the HIT in case of vestibular peripheral hypofunction. Because of this, in cases of moderated vestibular paresis (50-75\% of weakness) evaluated by the caloric test, the vast majority of patients (90\%) present negative $\mathrm{HIT}^{7,14}$. In this regard, the partial results of an ongoing study in which several clinical bedside tests were applied to 13 migraine patients and 6 control patients (21 to 60 years old), Maranhão et al. found positive HIT in $26 \%$ of patients and in none of the controls, while $46 \%$ of migrainous patients and $50 \%$ of controls showed assymetric nystagmus $(\geq 25 \%)$ in the minimal ice test, described by Leigh and Zee $\mathrm{Z}^{16}$ and Nelson ${ }^{17}$.

\section{HEAD IMPULSE TEST IN MEDICAL EMERGENCY}

In the emergency environment, the physical examination, diagnostic reasoning, and decision-making investigation (or therapeutic) requires accuracy, speed, and agility to distinguish the infarction of the posterior fossa of a more benign condition such as acute peripheral vestibulopathy (APV), which is not always easy. The computerized tomography is often not immediately revealing, specially in the
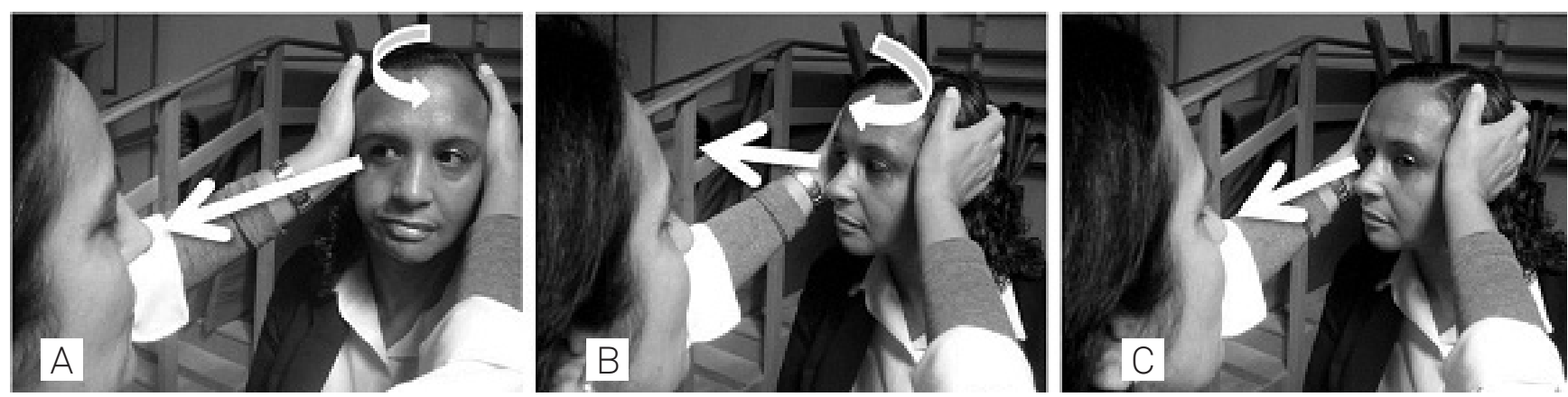

Figure. Head impulse test in right vestibular hypofunction. Initially the patient is instructed to visualy set a target located directly in front of the her face (example: nose of the examiner). (A) When the patient's head is turned sharply $\sim 15^{\circ}$ to the left, the eyes stay fixed on the target (normal response), out of phase with the head movement. (B) Next, the patient's head is rotated to the right side. Due to the impairment of the vestibular system on this side and loss of horizontal canal function, the patient can't keep the eyes on target, moving it in the same direction of head rotation and soon after (C) performing a quick corrective catch-up saccade that brings them back on target ${ }^{11}$. 
case of ischemia in the posterior fossa, and magnetic resonance imaging is not always available. Thus, once again, taking a smart, refined, and fast bedside examination can be a great tool to reach the correct diagnosis. It is worth mentioning that about $25 \%$ of APV who seek emergency care presenting nausea, vomiting, dizziness, nystagmus, and imbalance are actually posterior circulating infarcts ${ }^{18}$.

In order to verify the accuracy of the HIT in the differential diagnosis of APV versus vascular cerebellar (or brainstem) accident (VCA), Newman-Toker et al. ${ }^{19}$ investigated 43 patients. Eight out of eight with APV showed positive (100\%) HIT, while for 31 of 34 (91\%) VCA patients the test was negative. However, the HIT is not $100 \%$ reliable in detection of APV since some patients with stroke involving the lateral pontine root entry zone or cerebellar infarction may present a positive HIT. Moreover, $16 \%$ of cases of stroke in the lower portion of the cerebellum showed initial clinical presentation of pseudo-labyrinthine with unidirectional nystagmus (peripheral pattern) and positive response to HIT. The authors highlight that a negative HIT was more important than a positive.

Kattah et al. ${ }^{18}$, aiming to clinically differentiate between APV and stroke, extended the above-mentioned work by evaluating 101 patients with APV (nausea/vomiting, nystagmus, dizziness, intolerance to head movements, unsteady of gait). They concluded that the set of three signals obtained by bedside examination; the head impulse test, nystagmus that change direction according to the glance, and the skew deviation test (which show vertical strabismus) (HINTS), are able to differentiate a stroke in the brainstem/cerebellum from APV. It is noteworthy that the bedside eye movement examination may provide the only way to differentiate between the APV and VCA. Vertical strabismus predicts stroke involving the brainstem even in the presence of a false positive HIT (pseudo-labyrinthine). The negative HIT associated with a nystagmus that changes direction and skew deviation (vertical strabismus) were more sensitive in the diagnosis of stroke than early diffusion magnetic resonance imaging!

In conclusion, the HIT is a simple, practical, inexpensive, and indispensable method for evaluating unilateral or bilateral VOR dysfunctions with $100 \%$ specificity in cases of complete vestibular nerve lesion and which should always be used when differentiating between APV and VCA in the emergency room.

\section{ACKNOWLEDGMENTS}

To Péricles Maranhão Neto for his technical support.

\section{References}

1. Strupp M. Challenges in neuro-otology. Front Neurol 2010;1:121.

2. Neuhauser HK, von Brevern M, Radtke, et al. Epidemiology of vestibular vertigo: a neurotologic survey of the general population. Neurology 2005;65:898-904.

3. Fetter M. Assessing vestibular function: which tests, when? J Neurol 2000;247:335-342

4. Bronstein A, Lempert T. Dizziness: a pratical approach to diagnosis and management. Cambridge: Cambridge University Press, 2009.

5. Harsha JW, Phillips JO, Backous DD. Clinical anatomy and physiology. In: Weber PC (editor). Vertigo and disequilibrium: a practical guide to diagnosis and management. New York: Thieme Medical Publisher, Inc.,2008.

6. Leigth J, Brandt T. A reevaluation of the vestibule ocular reflex: new ideas of its purpose, properties, neural substrate, and disorders. Neurology 1993;43:1288-1295.

7. Jacobson GP, Shepard NT. Balance function assessment and management. San Diego: Plural Publishing Services, Inc, 2008.

8. Halmagyi GM, Curthoys IS. A clinical sign of canal paresis. Arch Neurol 1988;45:737-739.

9. Kerber KA, Baloh RW. The evaluation of a patient with dizziness. Neurol Clin Pract 2011;1:24-33.

10. Tusa RJ. Neuro-otology. History and bedside exam. Syllabus on CD ROM, Course 7PC.001. AAN 2012.
11. Halmegy GM, Cremer PD. Assessment and treatment of dizziness. J Neurol Neurosurg Psychiatry 2000;68:129-134.

12. Schubert MC, Tusa RJ, Grine LE, Herdman SJ. Optimizing the sensitivity of the head thrust test for identifying vestibular hypofunction. Phys Ther 2004:84:151-158.

13. Zee D. A Primer on vestibular eye movement disorders. Syllabus on CD ROM, Course 4PC-001. AAN 2009.

14. Herdman SJ. Vestibular rehabilitation. 3rd ed. E.A. Philadelphia: Davis Company, 2000.

15. Black R A, Halmagyi GM, Thurtell MJ, Todd MJ, Curthoys IS. The active head-impulse test in unilateral peripheral vestibulopathy. Arch Neurol 2005;62:290-293.

16. Leigh RJ, Zee DS. The neurology of the eye movements. 4th ed. Contemporary Neurology Series. New York: Oxford University Press Inc., 2006.

17. Nelson JR. The minimal ice water caloric test. Neurology 1969;19:577-585.

18. Kattah JC, Talkad AV, Wang DZ, Hsieh Y-H, Newman-Toker DE. HINTS to diagnose stroke in the acute vestibular syndrome three-step bedside oculomotor examination more sensitive than early MRI diffusionweighted imaging. Stroke 2009;40:3504-3510.

19. Newman-Toker DE, Kattah JC, Alvernia JE, Wang DZ. Normal head impulse test differentiates acute cerebellar strokes from vestibular neuritis. Neurology 2008;70:2378-2385. 